(1) Chavin is older than any period yet discovered on the north coast of Peru; (2) as a style Chavin has a wide distribution throughout Peru and bids fair to become a third pan-Peruvian period along with the Tiahuanaco and Inca periods; (3) the ramification of styles pertaining to Chavin together with its antiquity and distribution make it one of the basic factors in the revised chronology.

\section{CAUSES OF INTERTIDAL ZONATION}

$\mathrm{O}^{\mathrm{s}}$ N June 18 and July 9, the Linnean Society of London, under the chairmanship of the president, Dr. E. S. Russell, discussed the causes of the intertidal zonation of plants and animals. The discussion was opened by Prof. T. A. Stephenson, who attempted to elucidate the reasons for both the vertical zonation and the horizontal distribution round the coast of the common intertidal organisms of South Africa, as observed by himself and his collaborators during the years 1931-40 (see NATURE, $143,503 ; 1939)$. In his introductory remarks Prof. Stephenson stressed the importance of field observation, as well as that of laboratory and field experiment, for the interpretation of intertidal phenomena, and pointed out also that since much of what is observed between tidemarks is evidently due to the operation of complexes of factors, it is doubtful whether much is to be gained by too great insistence on the part played by each individual factor in a complex. After a review of a number of the factors which may be expected to be concerned in intertidal processes (nature of substratum, desiccation, temperature, wave-action, feeding-habits, competition for food and space, salinity, submergence and emergence, oxygen, carbon dioxide and hydrogen ion concentration, nutritive salts, light and taxes) the conclusion was reached that there is scarcely any factor the effect of which between tidemarks can be imagined which is unable to produce some effect on zonation, although certain factors are undoubtedly more important than others; and that the effect of some factors is much more local than that of others. It was further concluded that the principal agent responsible for the horizontal distribution of organisms around South Africa is sea temperature; that for zonation on open rock the controllers of primary importance are degree of exposure to the desiccation-heat-light complex acting together with degree of exposure to wave action ; that for zonation in rock-pools the leading factors appear to be variations in temperature and salinity ; and that light is probably more generally effective in determining the segregation of shadeloving from surface species than in contributing to the actual zonation. In all cases there are subsidiary effects due to causes other than the major ones.

Dr. J. S. Colman next contributed an account of some interesting intertidal enigmas, contenting himself with describing certain distributions for which explanation is urgently needed but which, up to the present time, remain quite unexplained. This contribution brought out very clearly what was recognized by all speakers, that although papers such as those contributed to this discussion introduce "an element of reason into a distribution which could previously best be described as orderly but irrational" Dr. Colman), yet the rationalizations hitherto attempted are undoubtedly too simple and very far from being able to explain all the facts observed.

The third speaker, Dr. E. M. Delf, dealt with the significance of the exposure factor in relation to zonation, enumerating its components : this contribution was in line with those of earlier speakers, and added reinforcement by means of a different selection of details, bringing out once again the fact that intertidal phenomena depend on complexes of interacting factors.

The meeting was then thrown open for discussion, and Dr. G. P. Bidder contributed a number of interesting examples taken from among the sponges, some of which threw additional light on points raised by previous speakers, while others introduced further features of intertidal life which had not previously been dealt with. Prof. L. Newton followed with some comments referring to algæ, noting particularly that, at least in Britain, the nature of the substratum may become important locally as a factor determining the nature of the flora; and that in past discussions on algal zonation the effects of light had probably been overestimated. Prof. Stephenson, Dr. Colman and Dr. Delf replied briefly to these comments.

On the resumption of the discussion on July 9, Mr. A. D. Cotton, in the unavoidable absence of the author, read a paper by Dr. V. J. Chapman on the horizontal distribution and vertical zonation of marine algæ on rocky shores. Dr. Chapman limited his attention to the common Fucoids. $\mathrm{He}$ found himself in agreement with Prof. Stephenson's opening remarks as to the validity of field-work as well as of experiments in the search for the causes of zonation, and also agreed that, of the factors controlling horizontal distribution, temperature appears to be the leading one. Passing to the question of critical levels between tidemarks, Dr. Chapman compared the work of several authors and synthesized their observations for five different localities, concluding that the existence of certain critical levels may be a reality despite undoubted local variations. In an assessment of the various factors the operation of which will render one level more critical than another, the effects were reviewed of mechanical exposure, substratum, submergence and emergence, exposure to air, temperature, illumination, salinity, gaseous exchange and nutrient salts, desiccation and biota. These factors were classified as causal, presence or absence and modifying factors respectively. Lastly Dr. Chapman considered the relation of algal zones to tidal levels in the light of the foregoing review, and pointed out lines along which further progress might be made in the search for the causes of zonation. Mr. Cotton, in reading the paper, added comments of his own referring to matters of detail, but no further discussion took place.

Regarded purely as a verbal discussion, this symposium was disappointing, because, as the result of an unfortunate combination of circumstances, several of those interested were unable to attend the second session of the discussion, and some of "them not even the first. At the same time there was a considerable measure of agreement between the views expressed, and the subject was seen to have been somewhat clarified during recent years in spite of universal recognition of its complex nature and of the need for extensive future investigation; and the papers contributed should, when printed in the Society's Proceedings, form a valuable reservoir of ideas for the further development of the subject.

T. A. Stephenson. 